\title{
Correction to: Progress and Limitations in the Treatment of Complex PTSD and Developmental Trauma Disorder
}

\author{
Julian D. Ford ${ }^{1, *}$
}

\author{
Address \\ *,1 University of Connecticut School of Medicine, Farmington, USA Department \\ of Psychiatry, University of Connecticut Health Center, 263 Farmington Ave. MC1410, \\ Farmington, CT 06030, USA \\ Email: jford@uchc.edu \\ Published online: 27 October 2021 \\ ๑ Springer Nature Switzerland AG 2021
}

The original article can be found online at https://doi.org/10.1007/s40501-020-00236-6.

\section{Correction to: Curr Treat Options Psych (2021) 8:1-17 https://doi.org/10.1007/s40501-020-00236-6}

The article Progress and Limitations in the Treatment of Complex PTSD and Developmental Trauma Disorder, written by Julian D. Ford, was originally published online on February 09, 2021, with Open Access under a Creative CommonsAttribution 4.0 International License. After publication in volume 8, issue 1, page 1-17, the author(s) decided to cancel the Open Access. Therefore, the copyright of the article has been changed on March 30, 2021, to ${ }^{\odot}$ Springer Nature Switzerland AG, part of Springer Nature 2021 with all rights reserved. The original article has been corrected.

\section{Publisher's Note}

Springer Nature remains neutral with regard to jurisdictional claims in published maps and institutional affiliations. 